explored by Spearman rank correlation coefficients $\left(r_{s}\right)$. We further applied supervised and unsupervised classification to investigate protein patterns by type of lung tissue.

Results Occupational exposure was associated with an up-regulation of NOTCH1 (radon: $\mathrm{r}_{\mathrm{s}}=0.18,95 \%$ CI 0.02-0.33; arsenic: $\mathrm{r}_{\mathrm{s}}=0.23,95 \%$ CI $\left.0.07-0.38\right)$. MUC1 classified lung cancer from cancer-free tissue (failure rate of $2.1 \%$ ), and HIF1A and NKX2-1 discriminated the major subtypes of lung cancer with a failure rate of $8.4 \%$.

Conclusions These results suggest that the radiation-sensitive protein NOTCH1 can be up-regulated in lung tissue from uranium miners by level of exposure to pulmonary carcinogens. The distinct phenotypes of the major subtypes of lung cancer could be discriminated with cancer-related proteins.

\section{SALIVARY CORTISOL AND DEPRESSION - IS THERE AN ASSOCIATION IN A RANDOM SAMPLE OF PUBLIC SECTOR EMPLOYEES?}

${ }^{1} \mathrm{M}$ A V Agergaard Vammen, ${ }^{2}$ Thomsen, ${ }^{2}$ Mikkelsen, ${ }^{2}$ Bonde, ${ }^{3}$ Hansen, ${ }^{4}$ Andersen, ${ }^{5}$ Buttenschøn, ${ }^{4}$ Grynderup, ${ }^{4}$ Kolstad, ${ }^{6}$ Kærlev, ${ }^{4}$ Kærgaard, ${ }^{7}$ Rugulies, ${ }^{5}$ Mors. ${ }^{1}$ BisBispebjerg University Hospital, Copenhagen NV, Denmark; ${ }^{2}$ Department of Occupational and Environmental Medicine, Bispebjerg University Hospital, Copenhagen, Denmark; ${ }^{3}$ Department of Public Health, University of Copenhagen and National Research Centre, Copenhagen, Denmark; ${ }^{4}$ Danish Ramazzini Centre, Department of Occupational Medicine, Herning, Denmark; ${ }^{5}$ Centre for Psychiatric Research, Aarhus University Hospital, Risskov, Denmark; ${ }^{6}$ Center for National Clinical Databases South, Odense, Denmark; ${ }^{7}$ National Research Centre for the Working Environment, Copenhagen, Denmark

\subsection{6/oemed-2013-101717.115}

Objective To examine if salivary cortisol is associated with depressive symptoms and clinical depression among public sector employees.

Method In 2007, 10,036 public sector employees received a questionnaire along with salivary cortisol test tubes for home administration. A morning (30 min after awakening) and evening $(2000 \mathrm{~h})$ salivary sample were collected. 3,536 employees returned questionnaires and valid saliva samples. A subsample of participants $(n=387)$ collected three morning saliva samples (at awakening, 20min and 40min after awakening) plus an evening sample $(2000$ h). Participants were approached again in 2009 with questionnaire and salivary test tubes $(n=2,408)$. Participants with self-reported depressive symptoms (Common Mental Disorder Questionnaire) were invited to a SCAN interview (Schedules for Clinical Assessment in Neuropsychiatry, version 2.1) to determine clinical depression. The repeated cross-sectional data were analysed with logistic regression. Odds ratios of depressive symptoms and of clinical depression were estimated for morning, evening, mean and the difference between morning and evening cortisol (slope). For the subsample, CAR (awakening cortisol response) and AUC (the area under the curve) cortisol measures were calculated. We adjusted for gender, age, income, education, family history of depression, physical activity and alcohol consumption.

Results In 2007 the median level of cortisol was $12.5 \mathrm{nmol} / \mathrm{l}$ in the morning and $2.1 \mathrm{nmol} / \mathrm{l}$ in the evening. None of the measures of salivary cortisol were associated with self-reported depressive symptoms or clinical depression, neither in 2007 or 2009. E.g. in 2007, the odds ratios of depressive symptoms by a one unit increase in morning and evening cortisol $(\log [\mathrm{nmol} / \mathrm{litre}$ saliva]) were 0.97 (95\% CI: 0.83-1.13) and 1.05 (0.92-1.20), respectively, and of clinical depression 1.08 (95\% CI: 0.35-3.36) and $0.66(0.30-1.45)$, respectively.
Conclusion Salivary cortisol was not associated to self-reported symptoms of depression or to clinical depression.

\section{EFFECTS ON CORTISOL IN SALIVA FROM GOING TO WORK AND OTHER SALIVA SAMPLING CIRCUMSTANCES. RESULTS FROM A LARGE EPIDEMIOLOGICAL STUDY}

${ }^{1} \mathrm{~S}$ M Mikkelsen, ${ }^{1}$ Thomsen, ${ }^{2}$ Andersen, ${ }^{1}$ Bonde, ${ }^{3} \mathrm{Grynderup},{ }^{3} \mathrm{Kolstad},{ }^{2} \mathrm{~K}$ ærgaard, ${ }^{4} \mathrm{Kærlev}$, ${ }^{1}$ Vammen, ${ }^{5}$ Hansen. ${ }^{1}$ Bispebjerg University Hospital, Copenhagen, Denmark; ${ }^{2}$ Regional Hospital Herning, Herning, Denmark; ${ }^{3}$ Århus University Hospital, Århus, Denmark; ${ }^{4}$ Odense University Hospital, Odense, Denmark; ${ }^{5}$ National Research Centre for the Working Environment, Copenhagen, Denmark

\subsection{6/oemed-2013-101717.116}

Objectives To examine the effects of going to work and other saliva sampling circumstances on the concentration of cortisol in saliva.

Methods The study is a cross sectional population study of 3536 working persons with

data on cortisol concentrations in saliva samples, one in the morning and one in the evening, and information on saliva sampling circumstances recorded by questionnaire.

We studied the effects on cortisol from sampling on a work day compared to a day off; number of hours worked; smoking; leisure time physical activity; sleep problems the night before sampling and other sampling circumstances. These factors were included as covariates in ordinary least square regression analyses with the log of cortisol in saliva (nmol/l) as the dependent variable. We adjusted for effects of age, sex and saliva sampling times and time from awakening.

Results Saliva sampling times were the major determinants of cortisol concentrations in saliva, including linear and quadratic effects. Morning cortisol was 23\% higher on work days than on non-work days ( $\mathrm{p}<0.0001)$, controlling for sampling and awakening times and other potential confounders. This effect was independent of age, indicating that the acute and rather strong HPA axis response to an anticipated stressor (going to work) was not attenuated by almost daily repeats during many years of work. Working seven hours increased the mean of morning and evening cortisol by $11 \%(\mathrm{p}<0.0001)$. Smoking, leisure time physical activity and use of painkillers also had significant effects.

Conclusions The anticipation of going to work seems to elicit a rather strong acute increase in morning cortisol. This response was not attenuated by increasing age as one would expect if frequently repeated HPA-axis activations eventually leads to a reduced HPA-axis response to acute stressors.

\section{METABOLOMICS EXPERIMENT AMONG WORKERS EXPOSED TO 2, 3, 7, 8-TETRACHLORODIBENZO-P-DIOXIN (TCDD)}

${ }^{1} \mathrm{~F}$ Saberi Hosnijeh, ${ }^{2}$ Pechlivanis, ${ }^{2}$ Keun, ${ }^{3}$ Portengen, ${ }^{4}$ Bueno-de-Mesquita, ${ }^{3}$ Heederik, ${ }^{1}$ Vermeulen. ' Utrecht University, Utrecht, The Netherlands; ${ }^{2}$ Imperial College, London, United Kingdom; ${ }^{3}$ Institute for Risk Assessment Sciences (IRAS), Utrecht University, Utrecht, The Netherlands; ${ }^{4}$ National institute for public health and environment (RIVM), Bilthoven, The Netherlands

\subsection{6/oemed-2013-101717.117}

Objectives Previous occupational studies suggest that 2,3,7,8-tetrachlorodibenzo-p-dioxin (TCDD) exposure may be associated 
with non-Hodgkin lymphoma (NHL) but findings are inconclusive. Mechanistic studies using global biochemical profiling (metabolomics) could provide supporting evidence for such an association by identifying relevant biological pathways. We applied metabolomics profiling to a cohort of TCDD exposed workers.

Methods 81 workers who had been exposed to either high (n $=43)$ or low $(\mathrm{n}=38)$ TCDD levels more than 30 years before serum collection and 63 non-exposed workers (from a comparable factory but without TCDD exposure) were included in the study. Serum ion metabolites were detected using Ultra high Pressure Liquid Chromatography (UPLC) coupled online to a Q-TOF Premier mass spectrometer with a scan range of 70 $1000 \mathrm{~m} / \mathrm{z}$. Current plasma levels of TCDD $\left(\mathrm{TCDD}_{\text {Current }}\right)$ were determined by high-resolution gas chromatography/isotope dilution high resolution mass spectrometry. TCDD blood levels at the time of last exposure (TCDDmax) were estimated using a one-compartment first order kinetic model. Differentially expressed metabolites were identified using partial least squares (PLS) regression, and Bayesian stochastic search variable selection with spike-and-slab priors of (nonlinear) generalised additive models.

Results Features that were present in all QC samples and had a coefficient of variation $\mathrm{CV}<30 \%$ were included in the present analyses ( $\mathrm{n}=421$ features). PLS and Bayesian stochastic search variable selection regression analyses revealed no obvious metabolic perturbations associated with TCDD serum levels.

Conclusions This is the first global metabolomic analysis related to TCDD exposure. No significant features were identified. It is concluded that TCDD exposure at levels present in this study does not lead to significant perturbations of the serum metabolites.

\section{Session: P. Other diseases}

\section{OCCUPATIONAL RISKS IN THE BUILDING AND PUBLIC WORKS SECTOR IN MOROCCO}

${ }^{1} \mathrm{H}$ Hami, ${ }^{2} \mathrm{~F}-\mathrm{Z}$ Azzaoui, ${ }^{2} \mathrm{D}$ Raougui, ${ }^{2} \mathrm{~A}$ Soulaymani, ${ }^{2} \mathrm{~A}$ Mokhtari, ${ }^{2} \mathrm{~A}$ O T Ahami. ${ }^{1}$ Kenitra, Morocco; ${ }^{2}$ Ibn Tofail University, Kenitra, Morocco

\subsection{6/oemed-2013-101717.118}

Objectives Occupational injuries represent a considerable part of the injury burden to society, affecting people in the most productive years of their lives. Building and public works sector is recognised by its high frequency of occupational injuries. Kenitra city is the most important city in the Gharb plain region (NW of Morocco) where different new constructions are installed. This study aims to describe the profile of occupational injuries occurring in the building and public works sector in Kenitra city.

Methods A descriptive retrospective analysis of occupational injuries notified in the delegation of employment of Kenitra in 2008-2009, was performed. The results do not include occupational diseases or journey accidents.

Results In 2008-2009, 305 workers were victims of an accident in the work, which 21 died. Victims are often men (91.8\%). According to data recorded, the risks in building and public works sector are higher than in other sectors (working at height, working on moving equipment, handling important). Accidents in this sector are caused by machinery, falling materials and falls from height. These accidents caused a temporary and permanent disability $(73.8 \%$ and $19.3 \%$ respectively).
Conclusions Occupational injuries could have serious consequences. Measures are needed to ensure safety and protect workers' health.

\section{RENAL EFFECTS INDUCED BY OCCUPATIONAL CO-EXPOSURE TO CADMIUM AND LEAD IN METALLURGY WORKERS}

${ }^{1} \mathrm{R}$ H Hambach, ${ }^{2} \mathrm{D}$ Lison, ${ }^{3} \mathrm{P}$ C D'Haese, ${ }^{4} \mathrm{~J}$ Weyler, ${ }^{5} \mathrm{E}$ De Graef, ${ }^{4} \mathrm{~A}$ De Schryver, ${ }^{3} \mathrm{~L} V$ Lamberts, ${ }^{4} \mathrm{M}$ van Sprundel. ${ }^{1}$ University of Antwerp/Occupational Health Service Mensura, Wilrijk, Belgium; 'Louvain Centre of Toxicology and Applied Pharmacology, UCL, Brussels, Belgium; '3aboratory of Pathophysiology, University of Antwerp, Antwerp, Belgium; ${ }^{4}$ Department of Epidemiology and Social Medicine, University of Antwerp, Antwerp, Belgium; Umicore PMR, Department of Health \& Safety, Hoboken, Belgium

\subsection{6/oemed-2013-101717.119}

Objectives Research on the effect of co-exposure to $\mathrm{Cd}$ and $\mathrm{Pb}$ on the kidney is scarce. The objective of the present study was to assess the effect of co-exposure to these metals on early renal biomarkers.

Methods $\mathrm{Cd}$ in blood (Cd-B), $\mathrm{Cd}$ in urine (Cd-U), $\mathrm{Pb}$ in blood $(\mathrm{Pb}-\mathrm{B})$ and urinary renal biomarkers i.e., microalbumin ( $\mu$-Alb), beta-2-microglobulin $\left(\beta_{2}-\mathrm{MG}\right)$, retinol binding protein (RBP), $\mathrm{N}$-acetyl- $\beta$-D-glucosaminidase (NAG), intestinal alkaline phosphatase (IAP) were measured in 122 metallurgic refinery workers examined in a cross-sectional survey. In order to explore the effect of $\mathrm{Pb}$ on the association between $\mathrm{Cd}$ and renal biomarkers (i.e., effect modification or interaction), we performed a multiple linear regression analysis (adjusting for age and pack-years of smoking) including an interaction term $\mathrm{Pb} \times \mathrm{Cd}$.

Results The median Cd-B, Cd-U, Pb-B were: $0.8 \mu \mathrm{g} / \mathrm{l}$ (IQR = $0.5,1.2), 0.5 \mu \mathrm{g} / \mathrm{g}$ creatinine $(\mathrm{IQR}=0.3,0.8)$ and $158.5 \mu \mathrm{g} / \mathrm{l}$ $(\mathrm{IQR}=111.0,219.3)$, respectively. The statistically significant interaction term $\mathrm{Pb}-\mathrm{B} \times \mathrm{Cd}-\mathrm{B}$ indicates that the impact of $\mathrm{Cd}-\mathrm{B}$ on the enzymes NAG and IAP was only evident among workers with $\mathrm{Pb}-\mathrm{B}$ concentrations $\geq 75^{\text {th }}$ percentile. The association between $\mathrm{Cd}-\mathrm{U}$ and the renal markers NAG and RBP was also evidenced when $\mathrm{Pb}-\mathrm{B} \geq 75^{\text {th }}$ percentile. No statistically significant interaction terms were observed for the associations between $\mathrm{Cd}$ $\mathrm{B}$ or $\mathrm{Cd}-\mathrm{U}$ and the other renal markers under study (i.e., $\mu-\mathrm{Alb}$ and $\beta 2-M G)$.

Conclusions Our findings indicate that $\mathrm{Pb}$ modifies (increases) the strength of the association between $\mathrm{Cd}$ and early renal biomarkers.

\section{RENAL DYSFUNCTION AND POLYMORPHISMS IN METALLOTHIONEIN 2A IN A CHINESE POPULATION EXPOSED TO CADMIUM}

C X Chang, J T Jin. Fudan University, Shanghai, China

\subsection{6/oemed-2013-101717.120}

Objectives Cadmium (Cd) toxicity of the kidney varies between individuals despite similar exposure levels. In humans $\mathrm{Cd}$ is mainly bound to metallothioneins (MT), which scavenge its toxic effects. Here we analysed whether polymorphisms in MT genes MT2A influence Cd-related kidney damage.

Methods In a cross-sectional study $\mathrm{N}=566$ volunteers were selected from three areas in South-Eastern China, which to varying degree were Cd-polluted from a smelter (control area [median Cd in blood B-Cd $=1.38 \mu \mathrm{g} / \mathrm{L}]$, moderately [B-Cd $=$ $4 \mu \mathrm{g} / \mathrm{L}]$ and highly $[\mathrm{B}-\mathrm{Cd}=9.5 \mu \mathrm{g} / \mathrm{L}]$ polluted areas). (control area [median $\mathrm{Cd}$ in urine $\mathrm{U}-\mathrm{Cd}=2.01 \mu \mathrm{g} / \mathrm{g} \mathrm{Cr}$ ], moderately 